\title{
HARDNESS OF HYBRID PVD-PECVD W-C:H COATINGS VS. SUBSTRATE TYPE
}

\author{
FrantišEK LofaJ*, Margita KabÁtová
}

\author{
Slovak Academy of Sciences, Institute of Materials Research, Watsonova 47, 04001 Košice, Slovakia \\ * corresponding author: flofaj@saske.sk
}

\begin{abstract}
The effects of substrate on the measurement of hardness (and indentation modulus) penetration depth profiles were investigated on hybrid PVD-PECVD W-C:H coatings made with the additions of $\mathrm{C}_{2} \mathrm{H}_{2}$ or $\mathrm{CH}_{4}$ using High Power Impulse Magnetron Sputtering (HiPIMS) method. The substrates involved 100Cr6 bearing steel, Al2024 aluminum alloy and (111) Si wafer. Although no clear influence of the substrate type on hardness and indentation modulus of the coatings at different acetylene and hydrogen additions was observed, when both measured properties were combined in $\mathrm{H}_{\mathrm{IT}} \mathrm{E}_{\mathrm{IT}}$ ratio, significant shift of $\mathrm{H}_{\mathrm{IT}} / \mathrm{E}_{\mathrm{IT}}$ ratio dependencies obtained on Al alloy vs. steel and $\mathrm{Si}$ wafer substrates occurred. Thus, the effect of substrate type on the measurementlevaluation was confirmed.
\end{abstract}

KEYWORDS: Hardness, indentation modulus, substrate effect, W-C:H coating.

\section{INTRODUCTION}

Tribological properties of hard coatings, especially their wear resistance, coefficient of friction (COF) depend on large number of parameters including loading and environmental conditions but also material system used for the coating, its structure, surface roughness and such properties as hardness, elastic modulus, and others. It was reported that the wear properties of hard coatings more strongly correlate with $\mathrm{H} / \mathrm{E}$ ratio than just with the hardness itself [1. Moreover, it was also found out that the $\mathrm{H} / \mathrm{E}$ and/or $\mathrm{H}^{3} / \mathrm{E}^{2}$ ratios are related to the level of plasticity and can be used to estimate changes in the toughness of the coatings [2]4]. This is of significant interest because toughness is among the main parameters, besides hardness, Young's modulus, COF, wear, scratch, oxidation and corrosion resistance of the coatings for engineering applications. The measurement of mechanical properties, involving hardness, elastic modulus and toughness in the coatings with the thickness in the range of few micrometers is a challenge even by nanoindentation because of the inevitable influence of the substrate on the measurement of the coating properties. To reduce this influence, the indentations depths used for the determination of coating hardness should be substantially smaller than the thickness of the coating. Physical explanation is that the stress field under the indenter, corresponding to the zone with the stresses above the yield stress (zone of plasticity), has to be fully confined in the coating. So called "10\% (of the coating thickness) rule" is often applied to determine such maximum depth and true hardness of the coating, respectively [5-10]. Another approach to eliminate substrate influence and to determine true coatings properties is to use hardness (and elastic modulus) - indentation depth profiles obtained from continuous multi-cycle (CMC) or continuous stiffness measurements (CSM) [1]. The coating properties correspond to the maximum or plateau on the corresponding depth profile at the depths smaller than $10 \%$ of the coating thickness. However, the liability of $10 \%$ rule is limited by the accuracy of the measurement at coating thicknesses below $1 \mu \mathrm{m}$ related to tip surface area calibration function, by indenter tip radius [12], surface roughness, pile-up or sink-in behavior [13], residual stresses as well as by the ratio between the yield stresses and the elastic moduli of the coating and the substrate, respectively [9, 14]. The measurements of indentation modulus are much more sensitive to substrate properties than hardness because the elastic stress field under the indenter would be much larger than the zone of plasticity and therefore, $10 \%$ rule may not be sufficient. Thus, the problem of proper measurement of hardness simultaneously with the elastic modulus in thin hard coatings persists and it is even emphasized by the applicability of the $\mathrm{H} / \mathrm{E}$ ratio for toughness and wear resistance estimations. In our earlier works, the influence of indenter tip radius on the hardness - depth profiles has been analyzed using a combination of the experimental and finite element modelling approaches [12]. However, the influence of the Young's modulus of the substrate on the nanoindentation measurements was not investigated. Therefore, the aim of the present work is to investigate the influence of the substrate properties on the measurements of hardness, and indentation modulus in thin hard coatings used for engineering applications. The measurements were performed on HiPIMS (High Power Impulse Magnetron Sputtering) W-C and W-C:H coatings deposited using hybrid PVD-PECD (Physical Vapor Deposition - Plasma Enhanced Chemical Vapor Deposition) process with different acetylene and hydrogen additions on three different substrates. 

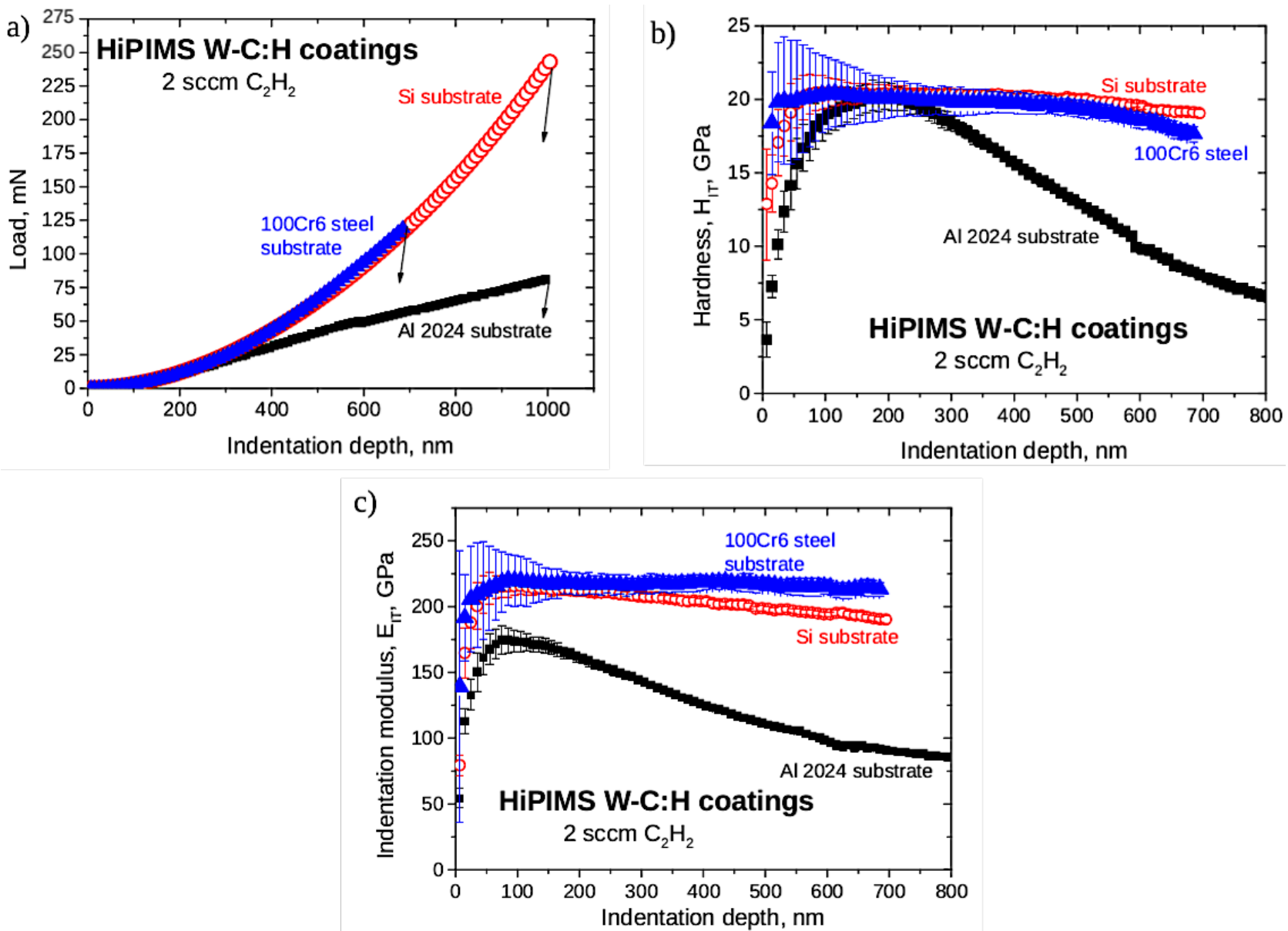

FIgURE 1. Load - indentation depth curves from the nanoindentation tests on the HiPIMS W-C:H coatings deposited with $2 \mathrm{sccm} \mathrm{C}_{2} \mathrm{H}_{2}$ on Si wafer, 100Cr6 bearing steel and Al 2024 alloy substrates - a) The depth profiles of hardness b) and indentation modulus $-\mathrm{c}$ ).

\section{EXPERIMENTAL MATERIAL AND METHODS}

The studied W-C:H coatings were simultaneously deposited on three different substrates: polished tempered bearing steel 100Cr6 discs (diameter - 25mm, thickness - 3mm ), polished Al2024 aluminum alloy discs with similar size and on approximately $1 \mathrm{~cm}^{2}$ polished (111) Si wafer fragments with $\sim 200 \mathrm{~nm} \mathrm{Cr}$ bond layer. The deposition was carried out at a minimum working pressure of $0.5 \mathrm{~Pa}$ in a magnetron deposition system (Cryofox Discovery 500, Polyteknik, Denmark) using High Power Impulse Magnetron Sputtering (HipIMS) source at $350 \mathrm{~W}$ average power achieved at $2.62 \%$ duty cycle related to the frequency of $150 \mathrm{~Hz}$ and impulse length of $175 \mu \mathrm{s}$. A set of 14 coatings with variable additions of $\mathrm{C}_{2} \mathrm{H}_{2}$ precursor $(0,2,4,6$, $8 \mathrm{sccm})$ and $(0,5,10,20 \mathrm{sccm})$ into Ar atmosphere was prepared for the study. The thicknesses of the coatings were in the range from $0.7 \mu \mathrm{m}$ up to almost $3 \mu \mathrm{m}$ depending on the amount of precursor gas additions 15 18.

The nanoindentation tests were carried out on a nanoindenter (model G200, Agilent, USA) using a diamond Berkovich tip in CSM mode with the preset maximum penetration depth of $1000 \mathrm{~nm}$, strain rate of $0.05 \mathrm{~s}^{-1}$, frequency of $45 \mathrm{~Hz}$ and amplitude of $2 \mathrm{~nm}$ on a set of 16 indents. The hardness and indentation modulus depth profiles were obtained by averaging the results of at least 10 measurements. The Young's modulus and Poisson's ratio of the diamond tip used for calculations were $E_{t i p}=1141 \mathrm{GPa}$ and $\nu_{t i p}=0.07$, respectively. The indenter tip was calibrated on a fused silica reference sample. The Poisson's ratios of the coatings of $\mathrm{v}=0.25$ was used for the evaluation of the corresponding properties.

\section{Results And Discussion}

\subsection{Substrate EFFECTS ON HARDNESS AND INDENTATION MODULUS IN HIPIMS W-C:H COATINGS}

Fig. 1a - 1 1 illustrate the differences between load - indentation depth curves, hardness - indentation depth and indentation modulus - depth profiles in the studied W-C:H coating deposited with the addition of 2 sccm $\mathrm{C}_{2} \mathrm{H}_{2}$, respectively. The load - displacement curve in the coating on $\mathrm{Al}$ alloy differs significantly from those on Si and steel substrates, which were practically identical, at the displacements above $400 \mathrm{~nm}$ 

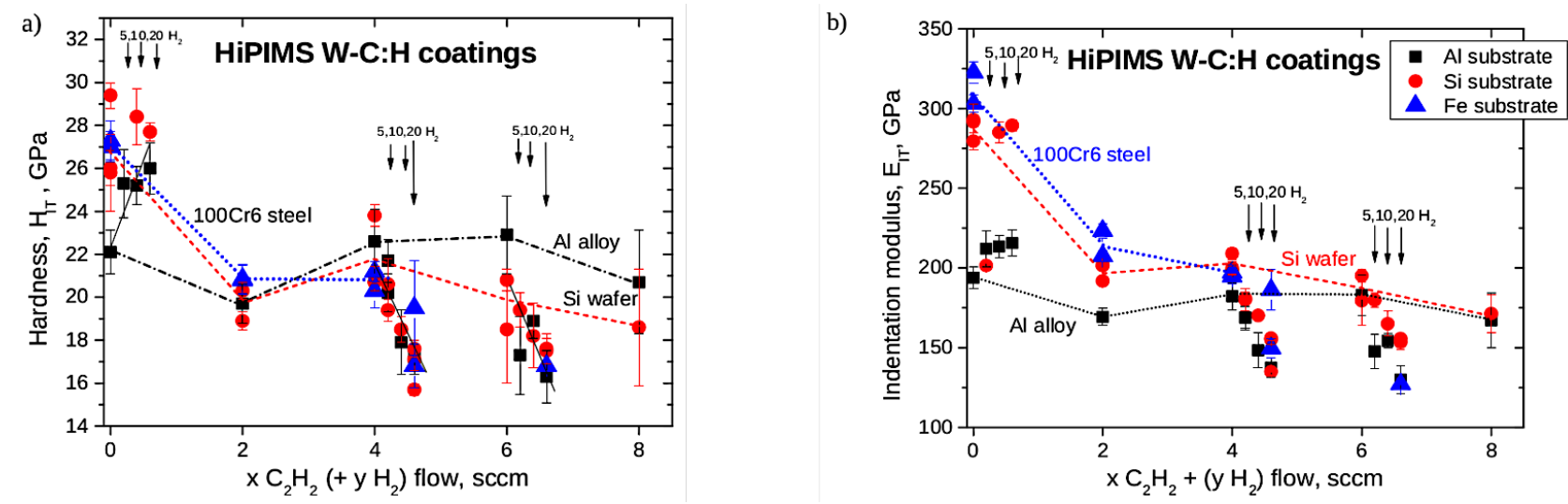

Figure 2. The comparison of the hardness, $\mathrm{H}_{I T-} \mathrm{a}$ ) and indentation modulus, $\left.\mathrm{E}_{I T-}-\mathrm{b}\right)$ in HiPIMS W-C:H coatings deposited at different acetylene (and hydrogen) additions on three types of substrates. The data-points corresponding to 5,10 and $20 \mathrm{sccm} \mathrm{H}_{2}$ additions were intentionally shifted by $0.2,0.4$ and $0.4 \mathrm{sccm}$ respectively, for better visibility.

(Fig. 17). However, this difference is not important for the determination of the hardness and indentation modulus, because they have to be determined from the indentation depths within the range of $100-300 \mathrm{~nm}$ due to the earlier mentioned $10 \%$ rule. Fig. $1 \mathrm{~b}$ shows the depth profile of hardness: on $\mathrm{Si}$ and steel substrates, very wide plateau at their maxima of around $20 \mathrm{GPa}$ extending up to almost $500 \mathrm{~nm}$ depth can be seen. In contrary, the influence of substrate is much stronger in the case of measurement on $\mathrm{Al}$ substrate: the onset of hardness decrease occurred already at $250 \mathrm{~nm}$. Such difference is a natural consequence of lower Young's modulus of $\mathrm{Al}$ alloy in comparison with steel and $\mathrm{Si}$ wafer. However, the maximum of the hardness profile obtained on Al alloy overlapped with those on the other two substrates and essentially no difference of the substrate on hardness can be seen. However, the situation was different in the case of indentation modulus profiles. A plateau at around $225 \mathrm{GPa}$ extending up to $500 \mathrm{~nm}$ can be seen on steel substrates but the measurement on $\mathrm{Si}$ wafer resulted in a maximum plateau at around $220 \mathrm{GPa}$ only up to $\sim 300 \mathrm{~nm}$. The effect of $\mathrm{Al}$ alloy substrate was much more pronounced: the maximum was around $175 \mathrm{GPa}$ and it extended only to $150 \mathrm{~nm}$ indentation depth. The values of $\mathrm{H}_{\mathrm{IT}}$ and $\mathrm{E}_{\mathrm{IT}}$ determined from the corresponding depth profiles according to the above mentioned way are summarized in Fig. 2 a and $2 \mathrm{p}$, respectively. They reveal number of effects and differences. They involve the effects of substrate type but also of acetylene and hydrogen additions during hybrid PVD-PECVD.

The PVD process without additional precursor gases resulted in (possibly over-stoichiometric [18]) WC coatings exhibiting much lower values of hardness $(22 \mathrm{GPa})$ and modulus $(<220 \mathrm{GPa})$ in the coatings deposited on $\mathrm{Al}$ alloy substrates than on $\mathrm{Si}$ and steel substrates (26 - $29 \mathrm{GPa}$ and 280 - $340 \mathrm{GPa}$, respectively). It is known from earlier works on DC magnetron sputtered and HiPIMS W-C:H coatings [17, 18] that the structure of the PVD coatings without additions of acetylene may vary from nano-columnar to nanocrystalline, which resulted in the variations of hardness from $34 \mathrm{GPa}$ to $28 \mathrm{GPa}$, respectively. The additions of acetylene caused gradual increase of the content of hydrogenated free carbon phase and a transition from nanocomposite to amorphous structure accompanied by a decrease of hardness [16 18]. The substrate itself may also play significant role in the formation of the coating structure and its morphology [15. Without detail structure observations, it is difficult to decide, which of the mentioned effects could be responsible for the changes of hardness and indentation modulus in the studied W-C coatings. As expected, the additions of acetylene resulted in gradual decrease of these properties. There were certain variations among the values obtained on various substrates, but they were within the scatter bars of the measurements and the differences decrease, especially in the case of elastic moduli (Fig. 2p). Apparently, the amorphization of the structure at high acetylene additions seems to result in the unification of the properties and has stronger effect than the possible influence of the substrate. Thus, the differences in coating properties deposited on different substrates seem to be statistically significant only in the cases without or with very small acetylene additions. However, they may interfere with the effects of coating structure and therefore, cannot be fully attributed to the substrate effect.

Figs. 2 also show the influence of hydrogen additions; it should be noted that the data-points corresponding to 5,10 and $20 \mathrm{sccm} \mathrm{H}_{2}$ additions were intentionally shifted by $0.2,0.4$ and 0.4 sccm from the position of the corresponding acetylene addition to show the tendency of the changes without overlap. It can be seen that the hydrogen additions have different effects on $\mathrm{H}_{\mathrm{IT}}$ and $\mathrm{E}_{\mathrm{IT}}$ in PVD W-C coatings and in hybrid PVD-PECVD W-C:H coatings made with acetylene additions. In the first case, hydrogen additions resulted in the increase of hardness and elastic modulus 
whereas they were decreased in the coatings made with $4 \mathrm{sccm}$ and $6 \mathrm{sccm}$ acetylene additions regardless of the substrate. Moreover, the corresponding values principally followed the dependencies described for the coatings without hydrogen additions and agree with the above conclusions concerning exclusivity of $\mathrm{W}-\mathrm{C}$ coatings compared to W-C:H coatings.

The above results indicate only a small influence of substrate type on hardness and indentation modulus. However, they are measured simultaneously and it is reasonable to check the simultaneous effect of both properties on different substrates. Thus, the results from Fig. 2a and $2 \mathrm{p}$ were replotted as a function of $\mathrm{H}_{\mathrm{IT}} / \mathrm{E}_{\mathrm{IT}}$ ratio on acetylene (and hydrogen) additions in Fig. 3. The obtained plots show that the acetylene and hydrogen additions usually result in gradual $\mathrm{H}_{\mathrm{IT}} / \mathrm{E}_{\mathrm{IT}}$ increase and that the difference between substrates was strongly magnified. Although the differences between $\mathrm{H}_{\mathrm{IT}} / \mathrm{E}_{\mathrm{IT}}$ in the coatings on $100 \mathrm{Cr} 6$ steel and Si substrates were negligible in the studied additions range, the corresponding values on $\mathrm{Al}$ alloy substrates followed the same tendency but they were by $0.02-0.025$ higher. Since both hardness and indentation modulus decrease with the acetylene addition increase, the increase of $\mathrm{H}_{\mathrm{IT}} / \mathrm{E}_{\mathrm{IT}}$ has to result from faster decrease of indentation moduli. Another consequence of the shift of the dependencies between steel, $\mathrm{Si}$ and $\mathrm{Al}$ alloy substrates was that all $\mathrm{H}_{\mathrm{IT}} / \mathrm{E}_{\mathrm{IT}}$ values obtained on $\mathrm{Al}$ alloy were above the plasticity limit of 0.1 while the identical coatings deposited on $\mathrm{Si}$ and steel substrates at 0 and $2 \mathrm{sccm}$ acetylene (and hydrogen) additions would be below that limit. Obviously, such systematic differences in $\mathrm{H}_{\mathrm{IT}} / \mathrm{E}_{\mathrm{IT}}$ on the same coatings do not have real physical reason. They have to be related to the influence of the substrate type on the measurement method and/or data evaluation rather than on true hardness and indentation modulus changes. It is a clear indication that the substrate type definitely affects the nanoindentation measurements. The question is what is the main parameter controlling the influence of the substrate. Young's moduli of steel and Si substrates are rather similar (210 GPa vs. $193 \mathrm{GPa}$ ) while that of Al alloy is considerably lower $(\sim 73 \mathrm{GPa})$ and this difference is reflected in the difference obtained Fig. 3 However, the yield strength and hardness of substrate materials should play a role because they control plasticity of the substrate

\section{Conclusions}

The investigations of the influence of the substrate type on the measurements of hardness and indentation modulus in HiPIMS W-C and W-C:H coatings with different acetylene and hydrogen additions on $\mathrm{Si}$ wafer, $100 \mathrm{Cr} 6$ steel and $\mathrm{Al} 2024$ aluminum alloy substrates revealed:

- Significant influence of substrate type on $\mathrm{H}_{\mathrm{IT}}$ and $\mathrm{E}_{\mathrm{IT}}$ in PVD W-C coatings deposited without the

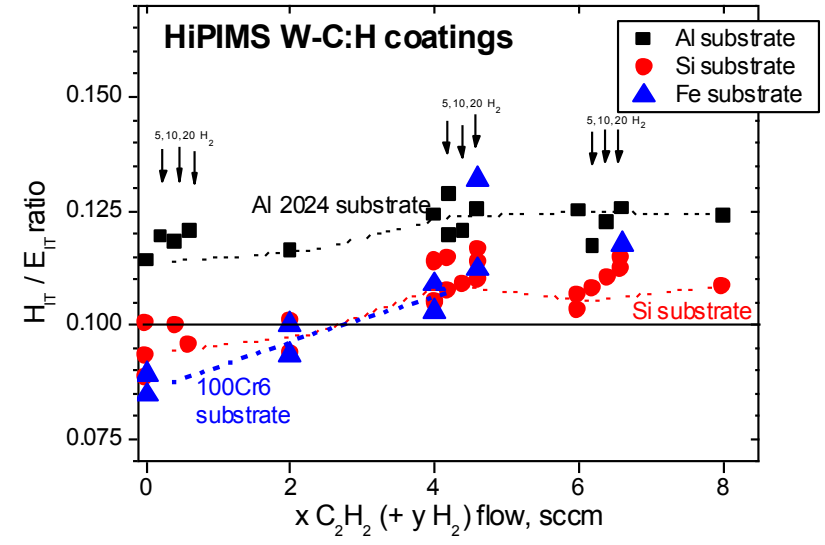

Figure 3. The dependence of $\mathrm{H}_{I T} / \mathrm{E}_{I T}$ ratio in HiPIMS W-C:H coatings on the substrate type at different acetylene (and hydrogen) additions. Note that the data-points corresponding to 5,10 and $20 \mathrm{sccm} \mathrm{H}$ additions to the corresponding acetylene flows were intentionally shifted to emphasize the role of hydrogen additions.

additions of acetylene. However, these differences may overlap with the influence of substrates on the coating structure.

- An enhanced scatter of the measured properties in hybrid PVD-PECVD W-C:H coatings with the additions of acetylene on the studied substrates. The differences between the substrates were within the scatter of measurement.

- When the effects of substrate type on hardness and indentation modulus were combined in $\mathrm{H}_{\mathrm{IT}} / \mathrm{E}_{\mathrm{IT}}$ ratio, significant shift between the dependencies obtained on $\mathrm{Al}$ alloy vs. steel and $\mathrm{Si}$ wafer substrates was obtained. Thus, the effect of substrate type on the measurement/evaluation was confirmed.

- The effect of substrate properties on nanoindentation measurements cannot be related only to the difference in Young's moduli of the substrates and further investigations are required to find the way to eliminate this influence.

The above conclusions imply that the reliable evaluation of the wear resistance and fracture toughness of thin coatings based on $\mathrm{H}_{\mathrm{IT}} / \mathrm{E}_{\mathrm{IT}}$ ratio requires the elimination of the influence of the substrate type on $\mathrm{H}_{\mathrm{IT}} / \mathrm{E}_{\mathrm{IT}}$ ratio.

\section{ACKNowledgements}

The support provided by the projects APVV-17-0320, APVV 17-0059, APVV-17-0049 and VEGA 2/0017/19 is acknowledged. The equipment used in the work was acquired from the projects "Research Centre of Advanced Materials and Technologies for Recent and Future Applications" PROMATECH, ITMS: 26220220186. 


\section{REFERENCES}

[1] A. Leyland, A. Matthews. On the significance of the h/e ratio in wear control: a nanocomposite coating approach to optimised tribological behaviour. Wear 246(1-2):111, 2000. DOI:10.1016/s0043-1648(00)00488-9

[2] J. Musil. Hard and superhard nanocomposite coatings. Surface and Coatings Technology 125(1-3):322-330, 2000. DOI:10.1016/s0257-8972(99)00586-1

[3] J. Musil. Hard nanocomposite coatings: Thermal stability, oxidation resistance and toughness. Surface and Coatings Technology 207:50-65, 2012. DOI:10.1016/j.surfcoat.2012.05.073.

[4] J. Musil, M. Jirout. Toughness of hard nanostructured ceramic thin films. Surface and Coatings Technology 201(9-11):5148-5152, 2007. DOI:10.1016/j.surfcoat.2006.07.020

[5] B. Jönsson, S. Hogmark. Hardness measurements of thin films. Thin Solid Films 114(3):257-269, 1984. DOI:10.1016/0040-6090(84)90123-8

[6] A. Korsunsky, M. McGurk, S. Bull, T. Page. On the hardness of coated systems. Surface and Coatings Technology 99(1-2):171-183, 1998. DOI:10.1016/s0257-8972(97)00522-7.

[7] R. Saha, W. D. Nix. Effects of the substrate on the determination of thin film mechanical properties by nanoindentation. Acta Materialia 50(1):23-38, 2002. DOI:10.1016/s1359-6454(01)00328-7.

[8] R. Saha, W. Nix. Soft films on hard substrates nanoindentation of tungsten films on sapphire substrates. Materials Science and Engineering: A 319321:898-901, 2001. DOI:10.1016/s0921-5093(01)01076-0.

[9] J. Chen, S. Bull. On the factors affecting the critical indenter penetration for measurement of coating hardness. Vacuum 83(6):911-920, 2009. DOI:10.1016/j.vacuum.2008.11.007

[10] X. Cai, H. Bangert. Hardness measurements of thin films-determining the critical ratio of depth to thickness using FEM. Thin Solid Films 264(1):59-71, 1995. DOI:10.1016/0040-6090(95)06569-5
[11] X. Li, B. Bhushan. A review of nanoindentation continuous stiffness measurement technique and its applications. Materials Characterization 48(1):11-36, 2002. DOI:10.1016/s1044-5803(02)00192-4.

[12] T. Csanádi, D. Németh, F. Lofaj. Mechanical properties of hard w-c coating on steel substrate deduced from nanoindentation and finite element modeling. Experimental Mechanics 57(7):1057-1069, 2016. DOI:10.1007/s11340-016-0190-x.

[13] A. Bolshakov, G. M. Pharr. Influences of pileup on the measurement of mechanical properties by load and depth sensing indentation techniques. Journal of Materials Research 13(4):1049-1058, 1998. DOI:10.1557/jmr.1998.0146.

[14] S. Kataria, S. Goyal, S. Dash, et al. Evaluation of nano-mechanical properties of hard coatings on a soft substrate. Thin Solid Films 522:297-303, 2012. DOI:10.1016/j.tsf.2012.09.001

[15] F. Lofaj, P. Hviščová, P. Zubko, et al. Mechanical and tribological properties of the high target utilization sputtering w-c coatings on different substrates.

International Journal of Refractory Metals and Hard Materials 80:305-314, 2019. DOI:10.1016/j.ijrmhm.2016.12.015.

[16] F. Lofaj, M. Kabátová, M. Klich, et al. Tribological behavior of hydrogenated w-c/a-c:h coatings deposited by three different sputtering techniques. Cerâmica 65(suppl 1):58-69, 2019. DOI:10.1590/0366-6913201965s12577.

[17] F. Lofaj, M. Kabátová, L. Kvetková, et al. Hybrid PVD-PECVD w-c:h coatings prepared by different sputtering techniques: The comparison of deposition processes, composition and properties. Surface and Coatings Technology 375:839-853, 2019. DOI:10.1016/j.surfcoat.2019.07.078

[18] F. Lofaj, M. Kabátová, J. Dobrovodský, G. Cempura. Hydrogenation and hybridization in hard w-c:h coatings prepared by hybrid PVD-PECVD method with methane and acetylene. International Journal of Refractory Metals and Hard Materials 88:105211, 2020. DOI:10.1016/j.ijrmhm.2020.105211. 